\title{
CERAMIC MEMBRANE ENABLING TECHNOLOGY FOR IMPROVED IGCC EFFICIENCY
}

\section{QUARTERLY TECHNICAL PROGRESS REPORT}

For Reporting Period Starting January 1, 2001 and Ending March 31, 2001

Principal Investigator: Ravi Prasad

DOE Program Manager: Ted McMahon

Report Issue Date: April 2001

DOE AWARD NO. DE-FC26-99FT40437

Submitted by:

Praxair, Inc.

175 East Park Drive

Tonawanda, NY 14150 


\section{DISCLAIMER:}

This report was prepared as an account of work sponsored by an agency of the United States Government. Neither the United States Government nor any agency thereof, nor any of their employees, makes any warranty, express or implied, or assumes any legal liability or responsibility for the accuracy, completeness, or usefulness of any information, apparatus, product, or process disclosed, or represents that its use would not infringe privately owned rights. Reference herein to any specific commercial product, process, or service by trade name, trademark, manufacturer, or otherwise does not necessarily constitute or imply its endorsement, recommendation, or favoring by the United States Government or any agency thereof. The views and opinions of authors expressed herein do not necessarily state or reflect those of the United States Government or any agency thereof.

\section{ABSTRACT:}

This quarterly technical progress report will summarize work accomplished for Phase 1 Program during the quarter January to March 2001. In task 1 careful modification of the composition and processing conditions of the OTM has enabled manufacture of high quality OTM elements. In addition, finite element modeling has been used to identify a suitable composition and geometry for successful pilot plant operation. In task 2, composite elements of materials with improved mechanical properties have been developed. In task 3, development of preferred fabrication methods has resulted in production of pilot plant scale composite elements. The work in task 4 has demonstrated that composite OTM elements can produce oxygen at atmospheric pressure of greater than 95\% purity from a high-pressure air feed gas. The work in task 5 to construct a multi-tube OTM reactor is ongoing. 


\section{TABLE OF CONTENTS}

A. Executive Summary $\quad$ Page 3

B. Experimental Methods Page 3

B.1. OTM Materials Development Page 3

B.2. Composite OTM Development Page 3

B.3. Manufacturing Development Page 3

B.4. Process Development Page 4

B.5. O-1 Pilot Reactor Development Page 4

C. Results and Discussion $\quad$ Page 4

C.1. OTM Materials Development Page 4

C.2. Composite OTM Development Page 4

C.3. Manufacturing Development Page 4

C.4. Process Development Page 4

C.5. O-1 Pilot Reactor Development Page 5

D. Conclusion Page 5

E. References Page 5

F. Appendix - Limited Rights Data Page A1 


\section{A. Executive Summary}

The objectives of the second year of the program are to define a material composition and composite architecture that enable the oxygen flux and stability targets to be obtained in high-pressure flux tests. Composite development technology will be developed to enable the production of high-quality, dense membranes of a thickness that allows the oxygen flux target to be obtained. The fabrication technology will be scaled up to produce three feet composite tubes with the desired leak rate. A laboratory scale, multi-tube pilot reactor will be designed and constructed to produce oxygen.

In the second quarter of the second year of the program, work has focussed on materials optimization, composite and manufacturing development and oxygen flux testing at high pressures. This work has led to several major achievements, summarized below.

- Finite element analysis has identified a composition and architecture that enables successful operation of the $\mathrm{O} 1$ pilot plant.

- Oxygen can be routinely produced from a composite OTM tube at the target purity level of greater than $95 \%$.

- Composite OTM elements have demonstrated stable operation at $\Delta \mathrm{P}>200 \mathrm{psi}$

- Pilot plant scale OTM composite elements have been successfully produced.

\section{B. Experimental Methods}

\section{B.1. OTM Materials Development Experimental Methods}

Characterization of OTM and substrate materials has been undertaken using many different experimental procedures. These include permeation, crystallographic, thermomechanical, thermochemical and electrochemical measurements. Standard equipment such as XRD, SEM, dilatometry and TGA/DSC were used. In addition oxygen permeation testers were used to measure the oxygen flux of OTM discs. The permeation test facility was described in the DOE IGCC first annual report ${ }^{1}$.

\section{B.2. Composite OTM Development Experimental Methods}

Various fabrication routes have been developed to prepare composite OTM samples. Small samples are first prepared and the fabrication routes that are most promising are further refined to enable larger OTM elements to be prepared. The fabrication routes used are proprietary information and included in the Appendix.

\section{B.3. Manufacturing Development Experimental Methods}

Fabrication routes developed in task 2 have been used for the manufacture of OTM elements for testing in the high-pressure permeation testers used in task 4. 


\section{B.4. Process Development Experimental Methods}

Composite OTM elements of the required geometry prepared using methods developed in prior work have been tested for high temperature permeation utilizing the high-pressure test facility and method previously described in the DOE IGCC first annual report ${ }^{1}$.

\section{B.5. O-1 Pilot Reactor Development Experimental Methods}

Commercial software has been used to determine mechanical stress and heat balance of the pilot scale reactor.

\section{Results and Discussion}

\section{C.1. OTM Materials Development Results and Discussion}

Optimization of OTM materials is ongoing with the view to improving properties required for commercial operation. In addition, FEM has been used to identify OTM element architectures suitable for successful $\mathrm{O} 1$ pilot plant operation using the current OTM materials.

New compositions with significant benefits in certain IGCC process conditions are being characterized. These compositions show substantial improvement over PSO1d in certain areas. Further work to improve other critical requirements is ongoing.

\section{C.2. Composite OTM Development Results and Discussion}

High quality composite elements of PSO1d on PSO1d can be routinely prepared using a variety of processing methods. These composite elements are gas tight and have enabled the production of high purity oxygen in the permeation testers. Composite elements comprising improved compositions have also been manufactured.

\section{C.3. Manufacturing Development Results and Discussion}

Improvements to the fabrication process were developed that has enabled the production O1 pilot plant scale composite OTM elements. Complementary technology is also being developed. Issues in batch to batch variations in powder quality are being addressed.

\section{C.4. Process Development Results and Discussion}

Composite tubes have routinely produced oxygen at atmospheric pressure with a purity greater than $95 \%$ under a large pressure differential of $>250$ psi. Further experimentation on composite OTM elements with improved architecture are expected to yield higher flux performance. 


\section{C.5. O-1 Pilot Reactor Development Results and Discussion}

The P\&I diagram for the $\mathrm{O} 1$ pilot plant was completed. Materials with suitable oxygen compatibility have been selected for fabrication of the OTM vessel. Details of the analytical system are being completed.

\section{Conclusion}

Good progress has been made in all tasks toward achieving the DOE-IGCC program objectives. In task 1, the materials and architecture required for $\mathrm{O} 1$ pilot plant operation were defined. In task 2, multiple fabrication processes have been developed that have enable gas tight composite membranes to be produced, resulting in high purity oxygen production. In task 3 improvements to the processing of OTM elements has led to the fabrication of pilot plant scale tubes. In task 4 , can be routinely produced at a purity of $>95 \%$. In task 5 the P\&I diagram has been finalized and materials have been selected for fabrication of the OTM vessel.

\section{E. References}

1. Prasad, Ravi, "Ceramic Membrane Enabling Technology for Improved IGCC Efficiency" 1st Annual Technical Progress Report for US DOE Award No. DEFC26-99FT40437, October 2000. 